\title{
Semántica y pragmática de la ironía verbal
}

\author{
Raymundo CAsas Navarro \\ Universidad Nacional Mayor de San Marcos \\ ¡Por Heracles! , tenemos a Sócrates \\ otra vez con su acostumbrada ironía. \\ Platón, La Rẹabibica (337a)
}

\begin{abstract}
Restmen
Se hace un estudio del multifacético y resbaladizo concepto de la ironía verbal con especial incidencia en sus aspectos semánticas y pragmáticas. Desde el punto de vista semántico, la ironía se reconoce como un discurso negativo indirecto que funciona gracias a la relación cognitiva de antonimia. En tal sentido, postulamos que los mensajes irónicos tienen en su forma lógica una negación invisible, pero siempre presente. Pragnáticamente, la ironía se entiende a la luz de la idea de los grados de saliencia aplicada al papel del contexto y se apoya considerablemente en la dinámica de la intención comunicativa.

La multiplicidad de factores que se ponen en juego en la interpretación irónica nos lleva a postular la necesidad del concepto de competencia irónica (como parte de la competencia retórica) . Este concepto intenta dar cuenta de las abigarradas estrategias aplicadas tanto en la producción del texto irónico (el rol del enunciador) como en la interpretación de las ironías por las que vivimos (el rol del enunciatario) .
\end{abstract}

Palabras claves: Ironía verbal, negación indirecta, grados de saliencia, intención comunicativa.

\section{Introducción}

$\mathrm{H}^{1}$ presente estudio toca un viejo tema de la retórica, pero desde el Hipunto de vista de la estructura del lenguaje cotidiano. En ese sentido, responde a la influencia del brillante estudio de George Lakoff 
y Mark Johnson (1980) acerca de las metáforas de la vida cotidiana. Tradicionalmente, las metáforas eran vistas como objetos propios y exclusivos de los poetas, pero la idea de Lakoff y Johnson fue analizar cómo nuestro lenguaje ordinario está gobernado por metáforas y las implicancias cognitivas que todo ello conlleva: esto es, cómo las metáforas configuran nuestras percepciones, nuestras categorizaciones, nuestras emociones. Por esta razón, el título del libro de estos autores es my revelador: Metaphors he Livive By. A raíz de este influyente trabajo, se vio con claridad que la metáfora constituye una experiencia múltiple en la que confluyen aspectos estilísticas, psicológicos, filosóficas y lingüísticos [Mac Cormac (1985), Chamizo (1998)] .

De manera similar al espíritu de estos semánticos cognitivos, nuestro objetivo es explorar cámo se configura la ironía en el lenguaje ordinario, cuál es la naturaleza de su procesamiento y cómo se logra su comprensión pragmática. Al proceder de esta manera con este tropo fundamental, retornamos al espíritu profundamente pragmático de la venerable retórica antigua. En efecto, la retórica antigua (que es la ciencia donde se configuraron de manera inicial los conceptos de metáfora, ironía, etc.) estaba fuertemente vinculada al uso efectivo del lenguaje. Sólo cuando la retórica antigua entró en decadencia por circunstancias históricas muy bien definidas [Todorov (1977)], sus conceptos perdieron fuerza y casi se convirtieron en posesión privativa de los poetas. Gracias al renacimiento de la retórica en la última mitad del siglo xx, se pudo replantear estos temas y estudiar los fenómenos retóricos en un escenario más amplio, trascendiendo el plano meramente literario. Un análisis ejemplar y fecundo de ello se puede ver en el trabajo citado de Lakoff y Johnson (1980) sobre la metáfora. En este estudio, trataremos de reconocer los aspectos semánticos de la ironía y ver cómo se relacionan con los componentes pragmáticos de las discursos irónicas.

El propósito mayor del estudio es desentrañar los mecanismos semánticos y pragmáticos de los enunciados (o actos de habla) irónicos. Para cumplir con este propósito, debemos satisfacer los siguientes dojetivos:

- Definir la ironía como acto de habla.

- Establecer la estructuración semántica del enunciado irónico. 
- Configurar las claves pragnáticas del acto de habla irónico, tanto en su construcción (rol del enunciador) como en su interpretación (rol del enunciatario) .

- Determinar la función del contexto en la interpretación del acto de habla irónico.

La importancia de este tipo de trabajo radica en que puede echar luces sobre una temática que adquiere cada vez más trascendencia: la relación entre cognición y lenguaje. En el dominio sintáctico, la teoría de la modularidad [Fodor (1983), Jackendoff (1987) ] y la clave de su procesamiento vertical han permitido avanzar mucho en esclarecer cómo funciona la mente humana. Por ello el dictum chomskiano del lenguaje como espejo de la mente ha servido de guía a una ingente cantidad de trabajos teóricos y empíricos sobre la sintaxis de las lenguas naturales. Sin embargo, en el dominio semántico las cosas no son de ese modo. En particular, la teoría de la modularidad y su abordaje vertical no pueden dar cuenta de muchos fenómenos ligados con la metáfora, la ironía, los eufemismos u otros aspectos muy sensibles al contexto. Por ello, en estos campos se han planteado con fuerza aproximaciones no modulares y horizontales [Gibbs (1994)] que exploran en la interrelación de diversos aspectos de la cognición humana. Aunque aún hay mucho debate acerca de estos temas, quizás se puede establecer con cierta firmeza que una aproximación cognitiva (esto es, no modular) puede tener mayor potencia explicativa. Ello ha acaecido en el importante tema de la metáfora. Desde muestro enfoque, creemos que se puede estudiar el fenómeno de la ironía justamente como un vehículo para entender mejor cómo funciona la mente, sobre todo la mente en sociedad [Verschueren (1999) ] .

El filósofo danés Kierkegaard (1841) afirmó que la vida humana no es posible sin ironía y todos recordamos la señera figura de Sócrates muy asociada a la ironía como una forma magistral de pensamiento filosófico. Así, pues, la ironía tiene una larga historia que ha ido ampliando su espectro con el tiempo, lo que ha generado que este viejo recurso de la mente se pueda expresar de múltiples maneras y en muchos sentidos. La ironía es, pues, un concepto resbaladizo que ha recibido en la última década del siglo pasado una atención trepidante en las ciencias cognitivas. Desde la retórica literaria, la ironía se ha 
definido como una figura retórica de supresión-adición que consiste en "presentar una expresión cuyo significado es contrario al que realmente tiene, si bien a partir del cotexto e incluso del contexto el receptor puede reconstruir el significante que el productor desea que se entienda" [Albaladejo (1993: 147) ] . Sin embargo, dado que la ironía en la forma de antífrasis plantea una relación in absentia debería considerarse como un tropo [Kerbrat-Orecchioni (1980), Holdcroft (1983), Kaufer (1983) ] y no como una figura. Para Kerbrat-Orecchioni (1980) , la ironía es un tropo de invención que actúa de la siguiente manera: Si el significado literal es claramente inconsistente con determinados hechos, la interpretación apunta a otro significado construido a partir del significado literal mediante una regla de transformación antinómica compatible con el contexto y el cotexto. Así, pues, en la ironía existe una contradicción entre lo que se dice y lo que se supone que se quiere decir, esto es, en la ironía se produce un extraño proceso de inferencia que suele denominarse antífrasis. Asimismo, la ironía es crucial para generar ciertos efectos de humor [Zavala (1993) ] .

En la lógica de los análisis pragmáticos de la ironía verbal, se ha sostenido [Kreuz \& Glucksberg (1989)] que en muchos enunciados irónicos se produce un caso especial de cita que se denomina "eco". En la ironía hay, pues, un distanciamiento de la proferencia efectiva que se manifiesta en el uso ecoico del lenguaje y sobre la base de diversos recursos como, por ejemplo, el tono de voz, ciertos gestos faciales, la referencia a acontecimientos pasados, etc. Estos recursos facilitan la tarea interpretativa del oyentey, en ese sentidb, son cruciales para dar cuenta de la comprensión de las ironías de la vida cotidiana.

Creemos que se ha avanzado mucho en el estudio de la ironía verbal, pero aún quedan aspectos que merecen ser dilucidados. En este marco, un enfoque como el que proponemos podría echar luces acerca de este fenómeno sobre la base del análisis de su condición estructurante (la noción de antífrasis, esto es, la contradicción semántica) y de sus condiciones pragmáticas (ligadas con el contexto, con el cotexto, con el concepto de intención) . Dado que la generación del enunciado irónico entraña la aplicación de una regla semántica (la de la antífrasis) que subyace a la forma superficial del enunciado, la interpretación de la 
ironía pone en juego una red de inferencias cuyo grado de complejidad está relacionado con la opacidad o transparencia del mensaje irónico.

Para aproximamos al tema, consideremos los siguientes enunciados como casos de ironía en el lenguaje ordinario. Dado que no son enunciados muy complejos, somos conscientes de que corremos el riesgo de transgredir los criterios ecológicas de las teorías cognitivas contemporáneas [Neisser (1976) ] que proscriben trabajar con "textoides" [Graesser, Swamer \& Hu (1997) ] y que recomiendan, más bien, analizar situaciones conversacionales que se dan efectivamente en la vida diaria [Gibbs (2000) ] . Sin embargo, partimos del supuesto de que una cierta idealización no es incompatible con el criterio de la validez ecológica, y que, en todo caso, operar con ejemplos simplificados puede constituir una adecuada hipótesis de trabajo.

(1) Pedro es tan "veloz" como una tortuga.

(2) La barra aliancista, en el Estadio de Matute, dio la "bienvenida" a los jugadores de la "U".

3) Como siempre, María estuvo muy "elegante" en la reunión del jueves.

(4) La propina que me dio mi tío fue muy "espléndida".

(5) Claudia es tan "ociosa" como una hormiga.

(6) Tu vida es muy "dura": te vas a Varadero cuando quieres.

El empleo de las comillas indica que no son ejemplos brutos, sino que ya se han analizado como irónicos. En la lengua oral, la ironía frecuentemente está asociada con cierta entonación característica (o con ciertos gestos como los guiños), pero el énfasis de tal entonación depende de muchos factores. En (1) la ironía no está del todo fuera del enunciado, ya que por razones de semántica cultural hay una antonimia patente entre "velocidad" y "tortuga" (por estereotipo, la tortuga es el animal no veloz). En tal sentido, la interpretación irónica se hace muy evidente para todo aquel que sepa que la "tortuga" culturalmente se considera un animal excesivamente lento. En los enunciados (2-4) , la ironía está fuera de la estnuctura lingüística y sólo se puede reconstruir con un conocimiento extratextual del referente. (2) es un enunciado evidente para todo aquel que conozca la historia del fútbol peruano. (3) es un enunciado cuya ironía depende del conocimiento personal de la mujer llamada María. (4) es un enunciado cuya ironía se puede reconocer por la descripción pragmática del contexto (el monto de la 
propina y su relación con las expectativas). Los emunciados (5) y (6) implican el mismo procesamiento que los anteriores, pero son de signo contrario: su significado intencional positivo se construye a través de un significado superficial negativo. Si bien (5) y (6) son enunciados irónicos, no son formas prototípicas de la ironía, pues su grado de saliencia [Verschueren (1999: 277-316)] es menor respecto de enunciados irónicos con evidente intención sarcástica.

La ironía como todo tipo de enunciado goza de los dos tipos de creatividad planteados por la lingüŕstica chomskiana, esto es, la productividad (siempre se pueden construir nuevos enunciados irónicos) y la creatividad cartesiana (la posibilidad de construir un enunciado que no dependa automáticamente del estímulo) . En tal sentido, sería una tarea imposible registrar todos los enunciados irónicos o hacer una taxonomía exhaustiva de las formas de la ironía. Además, muestro interés no está abocado a la performance irónica, sino a lo que podemos denominar competencia irónica (a nuestro juicio, la lingüística es una teoría de la competencia o de la cognición) . En tal sentido, estudiamos las performances irónicas sólo como epifenómenos que podrían revelarmos cómo se organiza la competencia irónica, tanto en la prooucción (generación) como en la recepción (interpretación) . Postularemos que la competencia irónica es un ejemplo de una competencia general: la competencia retórica, mediante la cual el hablante-oyente puede producir e interpretar un sinfín de enunciados (irónicas, humorísticas, metafóricos, metonímicos, hiperbólicas, etc.) . Estamos fundamentalmente de acuerdo con Booth cuando dice (1974: 78) "las reconstrucciones de la ironía no se pueden reducir casi munca, o munca, a gramática o a semántica o a lingüŕstica" .

\section{Antecedentes teóricos}

A partir de los estudios de Grice (1975) y Searle (1979) , se configuró el estudio de la ironía como un especial acto de habla caracterizado por una incongruencia entre el significado proferido y el significado intencional del hablante. La fecundidad de las ideas griceanas se puede notar en que dio pábulo a trabajos que se desarrollaron a partir de sus ideas medulares: 
- Ia semántica de script o de esquema de Raskin (1985) , inscrita dentro de la semántica cognitiva, intenta establecer un modelo formal de la competencia humorística: ¿qué combinaciones dan lugar a estructuras humorísticas y cuáles no? Para ello, siguiendo las ideas griceanas, elabora un principio de cooperación humorístico. Distingue dos tipos de comunicación: bona fide y non bona fide. Ia primera se relaciona con la mayoría de actos comunicativos, siempre que no se infrinjan los principios de cooperación formulados por Grice. La segunda se relaciona con dos tipos de comunicación, el humor y la mentira, como usas desviados del lenguaje. Así, la ironía, como una estrategia del humor, se concibe como una comunicación non bona fide $y$, en consecuencia, exige del oyente una mayor atención. Raskin (1985: 110-114) explica cómo el oyente transforma la información que considera fidedigna (esto es, de bona fide) en comunicación de non bona fide, al percatarse de la intención humorística del texto. Es decir, el oyente procesa el texto, nota la violación del principio de cooperación de buena fe, retrocede mentalmente y reinterpreta el texto como una broma. De ese modo, Raskin establece un principio de cooperación del humor sobre la base de la lógica de la conversación de Grice (1975) .

- S. Attardo (1993), asimismo, reflexiona sobre el carácter del texto humorístico que plasma un mensaje irónico a partir de una recapitulación de la doctrina sobre los principios de cooperación de Grice. En su explicación, da cuenta de cómo la ironía viola literalmente el contenido de las máximas conversacionales. Ahora bien, Grice distingue diversas actitudes en el hablante: éste cumple las máximas, las viola, se burla de ellas o saca provecho de las mismas. El caso más interesante es la violación de una máxima para cumplir con el objetivo de otra. ¿Favorece el chiste irónico un próspero intercambio comunicativo o, por el contrario, viola el principio de cooperación? Si tanto el hablante como el oyente persiguen el entendimiento, entonces se puede colegir que existe la intención fundamental de no violar el principio de cooperación. En este respecto, la ironía cumple con las estrategias cooperativas de la comunicación interpersonal. 
- En el trabajo de Curcó (1998) hay otra forma de concebir la incongruencia que se da en los actos de habla irónicos. Para este autor, un estímulo es incongruente cuando difiere del modelo cognitivo referente. De tal modo que la incongruencia es un instrumento para alcanzar el efecto humorístico, es decir, no es en sí misma un mecanismo generador de humor. De tal modo que la incongruencia es necesaria, pero no suficiente para la creación de un efecto humorístico o irónico, lo que también fue remarcado por Yus (1997). Piensa, además, que la teoría de la relevancia es un avance claro en la explicación pragmática de la conducta comunicativa humana porque nos permite comprender cómo se entienden los mensajes y en qué circunstancias concurrentes los mensajes varían su significación. Para Curcó el mecanismo generador de la ironía parte de una suposición básica de que hay una contradicción con la suposición previsible. Se invierte el grado de fuerzas mediante la contradicción. La suposición fuerte pasa a ser débil y viceverssa. La recepción de una incongnuencia indica al oyente la posibilidad de que el hablante expresa de manera implícita una actitud de distanciamiento con respecto a una de las suposiciones. curcó critica la idea de la existencia de unos principios del humor en nuestra mente. Es nuestra competencia gramatical la que nos permite producir y entender, sin esfuerzo, un número indeterminado de construcciones gramaticales, incluidos los enunciados irónicos. Nuestro punto de vista es que la competencia gramatical es necesaria, pero no suficiente, para entender los enunciados irónicos. Si Curcó tuviese razón, hasta los niños de cuatros años podrían producir y comprender enunciados irónicos, lo que no es el caso.

Los estudios anteriores se hallan en la línea de la semántica griceana, pero ello no quiere decir que esta teoría sea monolítica e infalible. Se han planteado algunas fuertes objeciones contra los postulados griceanos con respecto a la manera de entender el procesamiento de los disarrsos irónicos.

La teoría de Grice $(1975)$ y Searle $(1979,1993)$ se puede describir como la hipótesis de los tres estadios. De acuerdo con estos autores, el procesamiento de un acto de habla irónico se desarrolla en tres estadios secuenciales: a) Acceso al significado literal. b) Refutación del 
significado literal vía el contraste con el contexto. c) Intenpretación del significado no literal. El estadio c) entraña que se abandona definitivamente el estadio a). Hemos visto cómo algunos semánticos cognitivos han trabajado esta idea de desajuste o incongruencia. En términos de procesamiento, la hipótesis de los tres estadios explica que la mente accede al significado no literal sobre la base del acceso al significado literal. Según este modelo, el procesamiento de los mensajes irónicos (no literales) es más arcuo que el procesamiento de los mensajes literales por cuanto entraña un paso adicional: la inferencia del significado no literal.

En el influyente trabajo de Sperber y Wilson (1986) se objetó esta visión griceana sobre la base de la siguiente constatación: Ell significado no literal propio de los enunciados irónicos se deriva automáticamente a partir del contexto [Wilson \& Sperber (1992) ] . Si hay una inferencia, se trata de una inferencia inmediata. En consecuencia, como lo señaló sin ambages Rumelhart (1993), la mente nunca accede al significado literal. Esta posición, apoyada sobre la importante noción de relevancia, se ha rotulado como la hipótesis del procesamiento equivalente (esto es, no hay diferencias en el procesamiento de un mensaje literal con respecto al entendimiento de una ironía). Así, un enunciatario comprende un mensaje irónico como lo hace con un mensaje literal : el contexto permite recuperar directamente el verdadero significado del hablante, esto es, su intención comunicativa.

Se ha propuesto una tercera vía entre la teoría griceana y la teoría de la relevancia: la teoría de los grados de saliencia [Giora (1997) ] . De acuerdo con este enfoque, al interpretar un enunciado irónico, accedemos inicialmente al significado con mayor grado de saliencia. Ahora bien, el significado más saliente generalmente es el significado literal; sólo en ciertos casos (las ironías más convencionales o cristalizadas) el significado más saliente es el no literal. De acuerdo con esta explicación, se accede a los significados menos salientes en una segunda instancia, cuando debemos reconocer que los significados más conspicuos o sobresalientes no se adecúan a la situación commicativa. Esta teoría contradice la hipótesis de los tres estadios cuando el significado no literal tiene mayor grado de saliencia con respecto al significado literal. Asimismo, esta teoría contradice la 
hipótesis del procesamiento equivalente cuando el significado literal ostenta mayor grado de saliencia [Giora \& Fein (1999)] .

Hay un aspecto medular de la teoría de Grice que ha sido fuertemente revisado. Según la hipótesis de los tres estadios, una vez que se determina que el significado literal está descaminado, es totalmente abandonado. Giora (1995) considera que esta forma de ver las cosas no es adecuada porque, si bien el oyente reconoce que el significado literal es falso, no lo abandona, sino lo mantiene para construir su interpretación. Esto último hace mu diferente la interpretación de la ironía con respecto a la comprensión de la metáfora, [como fue apuntado por Booth (1974: 74) ] . El significado literal juega un rol importante en el significado del hablante: establece el contraste con el significado no literal. Por ello, hay una diferencia semántica entre el mensaje irónico ("Vaya, eres muy 'astuto'") y el mensaje no irónico ("Vaya, eres muy torpe") , porque en la ironía hay un juego contrastivo entre el significado literal y el significado irónico. Ello explica por qué en la ironía hay una coloración semántica especial que la hace diferente de la crítica directa o del elogio directo. La ironía, como negación indirecta, expresa a la sordina [Schwoebel et alii (2000)] un mensaje subyacente. Frente a la crítica directa ("Eres my tonpe") , la ironía ("Eres my 'astuto'") atenía el efecto crítico, lo hace menos negativo o hiriente. Frente al encomio directo ("Estuviste muy elocuente en la reunión") , la ironía ("Estuviste 'callado' en la reunión, ¿no?") debilita el efecto encomiástico, lo hace menos positivo: la alabanza irónica se constnuye, por así decirlo, am gramm salis. En la crítica irónica, el significado positivo literal tiñe el significado intencional negativo, lo que acarrea una morigeración de la crítica. En el loor irónico, el significado negativo literal tiñe el significado intencional positivo, con lo que se debilita el elogio. Las anteriores consideraciones abligan a dejar de lado la idea de una supresión del significado literal en los mensajes irónicos porque si este significado sufriese tal supresión, ¿cómo podría teñir al mensaje irónico como lo hace? 


\section{Marco teórico}

Para que nuestras hipótesis sean entendidas con perspicuidad, configuraremos un marco teórico que trate de sintetizar los aspectos semánticos y pragmáticos que apunten a señalar una competencia irónica como parte de un complejo mayor: la competencia retórica. Desde un principio, cabe poner de relieve que la competencia retórica de la que hablamos tiene como condición necesaria, pero no suficiente, la competencia gramatical. Además, como opera de manera horizontal, es no modular; en tal sentido el enfoque tiene que ser cognitivista. Ia semántica cognitiva fusiona dos tradiciones diferentes: los estudios de la psicología del procesamiento y los estudios de la lingüística cultural. En breve, la manera como los hablantes configuran sus producciones de sentido está determinada por procesos cognitivos que están en interacción con sistemas culturales globales [Palmer (1996)] .

La semántica tiene que ver con la interpretación de los enunciados en la forma lógica. La semántica opera con los principios de presuposición, entrañe, implicación y negación. En particular, el operador de negación funciona como un mecanismo de transformación de un valor de verdad en su contradictorio, de un efecto de sentido en su opuesto. De esa manera, se puede dar cuenta de multiplicidad de fenómenos como la sinonimia, la antonimia, la polisemia, el eufemismo, la hiperonimia, etc. La relación entre palabras, entre frases o entre textos se configura mediante el principio de coherencia. En tal sentido, la idea de que el hablante respeta el principio de coherencia a lo largo de su discurso es crucial para la semántica y para un modelo especial de la semántica: la semántica de las condiciones de verdad. La semántica de las condiciones de verdad es muy importante para explicitar las relaciones significativas, pero es insuficiente para dar cuenta del nexo entre semántica y cognición tal como se da en las diferentes lenguas naturales [Jackendoff (1983)] .

La pragmática [Reyes (1998)] está ligada al significado del hablante. Estudia los aspectos semánticos gobemados por el contexto y por el cotexto. Opera con máximas o estrategias de cooperación. La premisa fundamental de la pragmática es que todo acto de habla reposa sobre una intención comunicativa. Aunque la intención es un concepto 
filosóficamente problemático [Anscombe (1957) ], se puede entender de modo fenomenológico como una especie de descripción que hace inteligible una acción determinada. Para hablar con coherencia de intención no se necesita hurgar en los arcanos meandros del alma del hablante; basta con proponer una descripción que ajuste el significado con su contexto situacional. Fn ese sentidb, la postulación de una intentio operis [Eco (1990)] es clave para dar cuenta de una serie de fenómenos que, de otro modo, quedarían en el limbo umbral de la explicación. Para reconocer intención irónica [Muecke (1970)] basta con una descripción que tome implausible la interpretación literalista del enunciado y punto (no es un problema interesante que, después, el enunciador diga que esa no fue su intención, que en verdad no quiso ser irónico). Es más, la relación entre enumciador y significado irónico se puede entender como una metalepsis, esto es, como una posibilidad interpretativa [Genette (2004) ] . La intención comunicativa, así entendida, permite esclarecer la fuerza del enunciado como no puede hacerlo ninguna descripción formal o meramente léxica. El principio capital de la pragnática es la relevancia y su noción capital es la del acto de habla en la medida en que el acto de habla no puede sustraerse de la cadena commicativa. En este sentido, es crucial entender que todb acto de habla de bona fide tiende a maximizar la comunicación efectiva e integral, gracias a la relevancia. Ello explica la abundancia de redundancias en el lenguaje, inclusive la gramaticalización de las redundancias: los procedimientos deícticos.

Dado que la competencia irónica (como forma de la competencia retórica) opera con estrategias inferenciales, el marco teórico debe explicitar el sentido en que entendemos el proceso cognitivo llamado inferencia. Ahora bien, el proceso de la inferencia, desde un punto de vista cognitivo, forma parte del esquema mayor de la comprensión. En este sentido, el modelo propuesto por Anderson (1993) se revela como sólido y sugerente. Según Anderson, la comprensión entraña un procesamiento que consiste en recuperar información de la memoria operativa, sobre la base de la memoria declarativa, ejecutando la interpretación por la memoria de producción. La inferencia es un proceso natural de la mente que sirve para recuperar la información implícita, oculta o subyacente. 
La clave entonces es cómo la ironía nos brinda la información si dice todo lo contrario. Como queda dicho, se opera con inferencias, pero se pone en juego una dinámica especial. Al respecto, debemos considerar tres factores: la base presuposicional (la red de significados implicados en la construcción del mensaje) , el metamensaje (las claves dadas por los propios enunciadores sobre su mensaje) y la supresión de la violación del principio de cooperación de Grice (en particular, la máxima que obliga a hablar siempre con la verdad, con toda la verdad, con nada más que la verdad) .

Un factor fundamental en el entendimiento de la ironía es la saliencia. Esta importante propiedad pragmática y cognitiva consiste en reconocer que "no todo lo que ocurre en el comportamiento lingüŕstico ocupa el mismo lugar en la conciencia" [Verschueren (1999: 277) ] . Hay significados que destacan, que sobresalen más que otros. Si, en un contexto urbano, escuchamos la expresión "María está en el banco", el significado con mayor grado de saliencia será el significado de banco como institución financiera. En cambio, no será saliente el significado de banco como bajío arenoso en el mar. Ahora bien, la saliencia se puede construir por el contexto y el cotexto. Por ejemplo, si a lo largo de un texto se reitera que una persona no sabe nada de fútbol y el discurso termina con una frase irónica como: "En conclusión, ella sabe tanto de fútbol como yo de física nuclear", se puede decir que el mensaje irónico tendrá más saliencia con respecto al mensaje literal.

\section{ㅌl problema de investigación}

Nuestra investigación apunta a esclarecer si es necesario postular una competencia irónica (como forma de la competencia retórica) que dé cuenta de las diversas estrategias en la producción y en la interpretación de los actos de habla irónicos.

El problema de investigación, así planteado, nos dbliga a formularlo con las siguientes preguntas que traducen nuestras inquietudes cognoscitivas: 
- ¿Qué tipo de acto de habla es la ironía? O, como lo expresaría John Searle, ¿cuál es el punto ilocutivo de la ironía?

- Desde el punto de vista semántico, ¿cómo se estructura el enunciado irónico? ¿Cuál es su diferencia fundamental con los enunciados no irónicos? ¿Se puede dar cuenta de los enunciados irónicos con una semántica de condiciones de verdad?

- ¿Cuáles son las claves pragnáticas del acto de habla irónico, tanto en su construcción (rol del enunciador) como en su interpretación (rol del enunciatario)?

- ¿La función del contexto es homogénea en la interpretación de las ironías? o chay ironías que dependen crucialmente del contexto y otras curya interpretación puede prescindir de consideraciones contextuales?

\section{Hịpótesis, hipótesis, hịpótesis}

Para responder a la problemática presentada en el acápite anterior, vamos a proponer un conjunto de hipótesis que podrían configurar una teoría acerca de la ironía. Obviamente, por razones de espacio y por límites temporales, sólo estamos en condiciones de brindar los prolegómemos de la teoría y no podemos desarrollarla con todo detalle. Debemos remarcar que nuestro objeto de interés es la ironía en el lenguaje ordinario. En tal sentido, nos alejamos de autores como Booth (1974) que focalizan su interés en la lengua literaria. La propuesta central de muestra teoría es postular la necesidad de una competencia irónica (parte integrante de la competencia retórica) que explica la felicidad (condiciones de satisfacción) en la generación y en la interpretación de los mensajes irónicos. Aunque estamos de acuerdo con que esta competencia está anclada en la competencia gramatical, creemos que sus estrategias no se reducen al nivel meramente lingüístico y por esa razón se hace necesario un nuevo nivel de competencia lingüística: la competencia retórica. Además, hay una diferencia básica entre las dos competencias: la competencia gramatical entraña un procesamiento vertical, automático y modular; la competencia retórica entraña un procesamiento horizontal, integrado, 
esto es, no modular. Por ejemplo, la ironía no puede divorciarse de los mecanismos que una sociedad ha establecido para regular sus interacciones. Así, la ironía puede ser el rearso lingüístico para evitar conflictos, para hacer las llamadas críticas benévolas y, en ese sentido, se puede convertir en un factor de cohesión social. En este punto, viene a muestra mente la señera figura del sócrates platónico con su urbanidad, con su ironía sutil.

Con el fin de que se entienda mejor lo que proponemos, vamos a enunciar las hipótesis de manera esquemática:

HIrórrsss 1: El acto de habla irónico no se distingue por su forma o estructura. Dos enunciados con forma idéntica pueden tener distinto valor de cara a la intención comunicativa: uno puede ser irónico y el otro no. Por ejemplo: "iQué gordo, estás!" , puede ser una descripción, una hipérbole o una ironía, dependiendo del punto ilocucionario. El acto de habla irónico es un acto de negación indirecta que se define por el punto ilocucionario (o intención commicativa) que consiste en morigerar la fuerza del significado del hablante con el fin de provocar un efecto de atemuación de la crítica frontal (en el caso prototípico de la ironía, esto es, el sarcasmo). Mutatis mutandis, la misma consideración se aplica al elogio irónico (esto es, el encomio indirecto construido con una aparente censura) . La mención del punto ilocucionario nos doliga a precisar la condición semántica de la ironía y ello nos conduce a la siguiente hipótesis.

HIrórmsts 2: El mecanismo semántico de la ironía, en términos de las condiciones de verdad, reside en la antífrasis, esto es, la negación de la interpretación literal. En tal sentido, el mensaje irónico es incompatible con la designación o información referencial, razón por la cual se estructura un significado superficial versus un significado subyacente. Ahora bien, entre tales significados hay una relación de antonimia que se puede entender gracias a la semántica de las condiciones de verdad. Así, si decimos que "X es negro" es verdadero por implicación sabemos que "X no es negro" es falso. En la ironía, desde el punto de vista semántico, hay una negación (expresada por la entonación o por otros factores como los gestos) que permite al oyente 
interpretar el significado subyacente. Ia condición semántica exige la presencia subyacente de la negación que, en contra de lo que piensan los semánticos griceanos, no se cancela ni se suprime:

\section{ENNUNCIADO IRÓNICO:}

$$
\text { [Neg Op ø [Carlos es muty dadivoso] ] }
$$

Hay un operador de negación vacío (Op) que se encuentra en la forma lógica, pero que no es audible ni visible. Este operador es responsable de que la oración semánticamente sea negativa, esto es, la ironía debe entenderse como una negación enmascarada. En cambio, el enunciado no irónico es afirmativo:

\section{ENUNCIADO NO IRÓNICO:}

$$
\text { [ Carlos es muy dadivoso] }
$$

La negación subyacente puede tener alcances diversos y no es necesario que se proyecte a todo el discurso. Por ejemplo, si un individuo es un redomado impuntual, alguien puede decirle irónicamente "Puntual como siempre" ; pero la negación no incide en "siempre", sino en "puntual". Sobre la base de la incidencia de la negación, se podría determinar la existencia de un foco irónico responsable de la manera cómo debe entenderse el mensaje.

Ahora bien, en la medida en que es fundamental para la ironía recuperar (vía un mecanismo de inferencia) la negación subyacente que no es visible, que no es audible, y eso depende de condiciones muy variables, la semántica de las condiciones de verdad es necesaria, pero no suficiente para dar cuenta de los fenómenos de la ironía. El reconocimiento de este último punto nos conduce a la pragmática, esto es, a la tercera hipótesis.

Hirórissis 3: Las claves pragmáticas para recuperar la negación subyacente en la ironía tienen que ver con el manejo del contexto, el cotexto, y con un tipo de información dependiente del grado de saliencia del significado. En tal sentido, pragmáticamente, debe ponerse en marcha un principio de cooperación irónico. Es crucial que el enunciador garantice la recuperación de la ironía y mientras más comprometido esté en ello, la comprensión de la ironía se hará más fácil. En caso 
contrario, si el enunciador esconde más su intención, lo más probable es que la comprensión de la ironía sea un proceso arduo y hasta inasequible. Asimismo, es crucial que el oyente, apenas tenga una señal de posibilidad irónica, aguce su competencia irónica para recuperar la negación subyacente. Si el oyente no pone en ejecución su competencia irónica, caerá en una interpretación incorrecta o infel iz (misreading). Ia ejecución de la competencia irónica, en casos notables, depende del contexto; por esa razón vamos a la siguiente hipótesis.

Hiróniess 4: La función del contexto y del cotexto es crucial para la recuperación de la negación subyacente en el mensaje irónico. Ahora bien, puede darse el caso de que el enunciador, por cumplir con el principio de cocperación irónica, dé pistas textuales (o metalingüísticas) que hagan casi transparente la negación subyacente. Ello puede ocurrir en enunciados como el (1) presentado en la introducción o en enunciados con una ironía metalingüística (por ejemplo, cuando el hablante dice "es una ironía que..." ) . En tal sentido, la función del contexto no es homogénea para la interpretación de las ironías. Pueden darse tres casos:

- Debido a las pistas cooperativas del enunciador, el enunciatario puede prescindir del contexto para recuperar la negación subyacente y captar la ironía.

- La consideración del contexto es crucial para recuperar la negación subyacente y captar la ironía.

- Debido al hiperocultamiento de la negación subyacente por parte del enunciador, el contexto no permite recuperar la negación subyacente y se puede decir que la ironía tiene que captarse por otros medios.

La relación entre la negación subyacente y la función del contexto nos conduce a proponer el mecanismo cognitivo de la ironía, esto es, nos lleva a la quinta hipótesis.

Hró́nsis 5: Así como Darmesteter (1887) sostenía que la metonimia consistía en el mecanismo de la concatenación y la metáfora en los efectos de la radiación, se puede sostener que la ironía se construye con un mecanismo semántico característico: la noción de antonimia. 
La antonimia irónica (o antífrasis) no siempre se reconoce con claridad, pero consideramos que toda vez que haya una lectura irónica se puede reconstruir la negación en cualquier nivel del texto y operar, en consecuencia, una estrategia de inversión del significado referencial y de los efectos de sentido.

\section{Los datos y su interpretación}

Como hemos aclarado en la introducción, el conjunto de enunciados irónicos es ilimitado porque la creación irónica reposa en el principio de la creatividad. De esa manera, presentamos los siguientes datos sólo como exempla que ilustran los principios delineados en los apartados anteriores.

(1) Pedro es tan veloz como una tortuga.

2) La barra aliancista, en el Estadio de Matute, dio la "bienvenida" a los jugadores de la "U".

3) Como siempre María estuvo muy "elegante".

(4) La propina que me dio mi tío fue muy "espléndida" .

(5) Me siento tan "bien" que estoy como pez fuera del agua.

(6) Como cantante, eres un buen albañil.

(\) Aunque no sé nada de esto, quiero explicar lo que pienso.

(8) Es irónico que el crítico de las computadoras sea un fanático de la Internet.

(9) John Oliver escribió el tratado más documentado sobre historia medieval.

(10) Eres un cadáver que camina.

(11) El hombre es un mono desnudo.

(12) Carlos es muy brut. .., peroón, es muy inteligente.

(13) Ya que conoces tanto del tema, explícamelo porque yo soy un ignorante.

(14) No miento, lo juro, que me parta un rayo si estoy mintiendo.

(15) Gané, gané, gané... una sonora bofetada.

(16) Tuvo una ascensión vertiginosa hacia la nada.

(17) Con la lipoescultura perdí muchos kilos y también algunos pocos dólares. 
(18) Intenta hacer algo bien, para variar.

(19) Ia ironía básica del cristianismo es que la Biblia fue supervisada por un pagano.

(20) Entré a la habitación con mucho sigilo y cuando la iba a besar, besé a. . la almohada.

(21) Llegué puntual a la reunión, exactamente cuando acababa.

(22) Papá, papá, felicítame, me saqué un veinte. . . al revés.

(23) Realmente, la quiero mucho, sobre todo cuando está lejos.

(24) Soy un seguidor de Nietzsche y admiro mucho al cristianismo.

Los 24 enunciados anteriores son como la punta de un iceberg de un fenómeno de mayores dimensiones. Esconden, en realidad, un número ilimitado de enunciados irónicos. No sólo se pueden construir muchos más enunciados, sino que podrían construirse enunciados con nuevas formas de la ironía, dada la creatividad lingüŕstica como es entendida por la lingüŕstica chomskiana. Sin embargo, todas las formas de la ironía son proyecciones de un mecanismo formal idéntico: la presencia de una negación subyacente. Además, hay claves pragmáticas que giran en torno a la recuperación de esa negación subyacente y que sólo se pueden entender como la plasmación de una intención irónica. En lo que sigue, vamos a proceder a hacer una ordenación de los ejemplos anteriores (1-24) en virtud de ciertas características comunes de su procesamiento.

PRाMER Grpo: En este conjunto, la ironía se construye con pistas textuales que permiten recuperar la negación subyacente de la ironía. En (1) hay una antonimia entre "veloz" y "tortuga", en (2) entre "estar bien" y "pez fuera del agua", en (3) entre "cantante" Y "albañil", en (4) entre "cadáver" y "caminar", en (5) entre "ascensión" y "la nada", en (6) entre "mono" y "hombre" . En el conjunto, en consecuencia, casi se puede prescindir del contexto para determinar la ironía: el significado irónico resulta ser el más saliente. Ia antonimia in praesentia permite inferir con mucha seguridad la negación subyacente. Por esta razón, se puede hablar aquí de una ironía estable, en los términos de Booth (1974) , por cuanto los enunciados sólo se pueden interpretar en sentido irónico, cualquier otra lectura se presenta como desviada: 
(1) Pedro es tan veloz como una tortuga.

(2) Me siento tan "bien" que estoy como pez fuera del agua.

(3) Como cantante, eres un buen albañil.

(4) Eres un cadáver que camina.

(5) Tuvo una ascensión vertiginosa hacia la nada.

(6) El hombre es un mono desnudo.

SEGUNDO GRUPO: En este grupo, la ironía se ayuda con un mecanismo metalingüístico, a saber, el mismo enunciado dice explícitamente que es irónico. Además puede haber otras pistas como en (2) que presenta una antonimia in praesentia entre "cristianismo" y "pagano". La recuperación de la negación subyacente se facilita en un fuerte grado:

(1) Es irónico que el crítico de las computadoras sea un fanático de la Intemet.

2) Ia ironía básica del cristianismo es que la Biblia fue supervisada por un pagano.

Thrar Grupo: En este grupo, el reconocimiento de la ironía depende del contexto aultural, esto es, de informaciones extralingüristicas. En (1) se debe saber que en el Perú los equipos de fútbol Alianza y la "U" son rivales; razón por la cual es incompatible referencialmente el acto de "bienvenida" . En (2) se debe saber que por cuestiones culturales la puntualidad se refiere a la hora de inicio. En (3) sabemos que en el sistema educativo peruano un veinte al revés es una pésima nota y, en consecuencia, no merece felicitación. En (4) se debe saber por información extratextual que una operación de lipoescultura no es barata. Dado que el conocimiento del contexto cultural implica grados, por lo mismo el reconocimiento de la ironía de estos enunciados también manifiesta grados. Hay enunciados cuya ironía podría no ser percibida.

(1) La barra aliancista, en el Estadio de Matute, dio la "bienvenida" a los jugadores de la "U".

(4) Llegué puntual a la reunión, exactamente cuando acababa.

(3) Papá, papá, felicítame, me saqué un veinte ... al revés.

(4) Con la lipoescultura perdí muchos kilos y también algunos pocos db́lares. 
Claruo grupo: En este grupo, para percatarse de la ironía se requiere saber los antecedentes referenciales de los sujetos involucrados y probablemente la entonación (u otras actitudes corporales) ayude mucho en ello. El contexto cultural aquí es irrelevante; más bien, se debe apelar al conocimiento que se tiene de los individuos involucrados. Ahora bien, los enunciados (1-3) admiten también una interpretación literal, esto es, una lectura no irónica. En tal sentido, en términas de Booth (1974), habría una ironía inestable.

(1) Como siempre María estuvo muy "elegante" .

(2) No miento, lo juro, que me parta un rayo si estoy mintiendo.

(3) Intenta hacer algo bien, para variar.

QunNo Grup: En este grupo, para cerciorarse de la ironía, se requiere saber la referencia ocasional, esto es, la del mismo evento con sus hitos espacio temporales. Se trata, por cierto, también de una ironía inestable, por cuanto la interpretación literal es también coherente, verosímil, plausible.

(1) La propina que me dio mi tío fue muy "espléndida" .

(2) Realmente, la quiero mucho, sobre todo cuando está lejos.

SExTO Grupo: En este grupo, la ironía se refiere al mismo sujeto que habla. Por lo tanto, estamos ante el fenómeno de la autoironía. En el campo filosófico, esta forma de ironía ha sido, por antonomasia, practicada por Sócrates (esto es, la celebérrima ironía socrática) . Tiene una función eminentemente dialéctica y es muy sutil, razón por la cual su reconocimiento no siempre se logra y, en consecuencia, el efecto irónico resulta inadvertido.

(1) Aunque no sé nada de esto, quiero explicar lo que pienso.

(4) Ya que conoces tanto del tema, explícamelo porque yo soy un ignorante.

SÉPTIMO GRUPO: Aquí la ironía debe ser estable para cumplir con su objetivo, a saber, el efecto de humor. Aunque se puede decir que todas las ironías tienen un talante humorístico, los casos de este grupo son representativos de una especial intención en producir un efecto de risa 
(o de sonrisa). Por ello, se pueden denominar ironías humorísticas. Los puntos suspensivos (en la lengua oral, el tonema de suspensión) ayudan a lograr el efecto. El reconocimiento de la ironía no debe ser una tarea mur arcua para garantizar el efecto humorístico; por esa razón se trata de ironías que revelan cierto automatismo.

(1) Carlos es muy brut..., perdón, es muy inteligente.

(2) Gané, gané, gané... una sonora bofetada.

(3) Entré a la habitación con mucho sigil lo y cuando la iba a besar, besé a... la almohada.

Octä arpo: Este grupo final de ironías es el más difícil de interpretar. Su mecanismo irónico entraña un proceso más arduo y ello es del iberado. Se puede hablar de una ironía el itista o iniciática que, desde el principio, sólo podría ser reconocida por los que "saben". Si este proceso de ocultamiento se hace más intenso, inclusive se podría llegar a la ironía criptoestructural cuya estructura se mantiene oculta o es ignorada por todos los observadores. Por ejemplo, no sabemos si la célebre frase de la Biblia: "Y seréis como dioses" encierra o no una ironía. En (1) los conocedores de historia medieval sabrán que ningún John Oliver escribió tratado alguno al respecto. En (2) los conocedores de la filosofía de Nietzsche se darán cuenta de su sentido irónico, por cuanto Nietzsche es el crítico más mordaz del cristianismo.

(1) John Oliver escribió el tratado más documentado sobre historia medieval.

Q) Soy un seguidor de Nietzsche y admiro mucho al cristianismo.

\section{Conclusiones}

Considerando que la ciencia es un saber conjetural, falible y perfectible, las conclusiones a las que hemos llegado tienen el sello de la provisionalidad. Están abiertas a la crítica intersubjetiva y al proceso de retroal imentación que garantizan el progreso científico.

1 La ironía es un acto de habla indirecto cuyo punto ilocucionario se relaciona con una estrategia pragnática que va de la ausimanifestación de la intención irónica hasta el críptico ocultamiento de la misma. 
2. En tanto que acto de habla indirecto, su interpretación conlleva la ejecución de inferencias que permiten deducir la intención irónica a partir de un significado manifiesto contrario (esto es, la antífrasis) .

3. Desde el punto de vista semántico, en la forma lógica del enunciado irónico hay una negación subyacente que no es visible en la estructura de superficie. Recuperar esa negación subyacente es la clave de la intenpretación irónica.

4 Desde el punto de vista cognitivo, la ironía se procesa como una antonimia por la cual el enunciado irónico se intenpreta gracias al contraste entre el significado literal y la intención irónica expresada a la sordina.

5. Dado que hay mecanismos de revelación-ocultación de esa negación subyacente, la semántica de las condiciones de verdad es necesaria, pero no suficiente para la intenpretación irónica.

6. La gama de factores que se ponen en juego en la interpretación irónica (contexto, cotexto, etc.) nos llevan a la pragmática. En tal sentido, postulamos como tesis central la necesidad del concepto de competencia irónica (como parte de la competencia retórica) para dar cuenta de la multiplicidad de estrategias del enunciador irónico y del enunciatario irónico.

\section{Referencias bibliográficas}

ALBAIADEJO, Tomás (1993) : Retórica. Síntesis. Madrid.

ANDERSON, J. R. (1993) : Rules of mind. Lawrence Erlbaum. New Jersey.

ANscomBE, G. E. M. (1957) : Intention. Blackwell. Oxford.

ATTARDO, S. (1993) : "Violation of Conversational Maxims and Cooperation: the Case of Jdkes". Joumal of Pragnatics, 19, pp. 537-558.

BOOHH, Wayne (1974) : Retórica de la ironía. Taurus. Madrid, 1986.

CHAMIZO, Pedro (1998) : Metáfora y Conocimiento. Analecta Malacitana. Mb́laga.

đRCó, C. (1998) : "Indirect Echoes and Verbal Humour". En V. Rouchota y A. Jucker (eds. ) : Arrent Issues in Relevance Theory. John Benjamins. Amsterdam, pp. 305-325. DARVESIEIHR, A. (1887) : La vie des mots étudiée dans leurs significations. Delagrave. País. 
ECO, Unberto (1990) : Los límites de la interpretación. Lumen. Barcelona, 1992. FODOR, Jerry (1983) : La modularidad de la mente. Mbrata. Madrid, 1986.

GENEIIE, Gérard (2004) : Metaleposis. De la figura a la ficción. FCE. Buenos Aires, 2004.

GIBBS, Raymond (1994): The poetics of mind. Cambridge University Press. Cambridge. GIBBS, Raymond (2000) : "Irony in talk among friends". Metaphor and Symbol, 15 (1 \&2) , pp. 5-27.

GIORA, R. (1995) : "On irony and negation". Discourse Processes, 19, 239-264.

GIORA, R. (1997) : "Understanding figurative and literal language: The graded salience hypothesis". Cognitive Linguistics, 7, 183-206.

GIORA, R. y FEIN, O (1999) : "Irony comprehension: The graded salience hypothesis". Hhmor, 12, 425-436.

GRAESSER, A; SWAMER, S y HU, X. (1997) : "Quantitative discourse psychology". Discaurse Processes, 23, pp. 229-263.

GRICE, H. P. (1975) : Logic and conversation. Harvard University Press. Cambridge, MA. HOLDCROFT, David (1983) : "Irony as a trope, and irony as discaurse". Poetics Toolay 4:3, pp. 493-511.

JACKENDOFF, Ray (1983) : Semantics and cognition. MIT Press. Cambridge, MA.

JACKENDOFF, Ray (1987) : La conciencia y la mente computacional. Visor. Mbokrid, 1998. KAUFER, David (1983) : "Irony, intenpretive form, and the theory of meaning". Poetics Today 4:3, pp. 451-464.

KERBRAT-ORECCHIONI, Katherine (1980) : "L' ironie comme trope" Poétique 41, 108127.

KIHRKKEGAARD, Sören (1841): The concept of irany with constant reference to Socrates. Collins. London, 1996.

KREUZ, R. y GLUCKSBERG, S. (1989) : "How to be sarcastic: The echoic reminder theory of verbal irany". Joumal of Experimental Psychology, 118, pp. 374-386.

LAKOFF, G. y JOHNSON, M. (1980) : Metáforas de la vida cotidiana. Cátedra. Madrid, 1986.

MAC CORMAC, Earl (1985): A cognitive theory of metaphor. MIT Press. Cambridge, MA.

MUECKE, D. C. (1970) : Irony and the Ironic. Methuen. London. 
NEISSHR, U. (1976) : Cognition and reality. Freemen. San Francisco.

PAIMER, Gary (1996) : Lingüística alltural. Alianza. Madrid, 2000.

RASKMN, Victor (1985) : Semantic Mechanisms of Humor. Reidel Publishing Company. Dordrecht.

REYES, G. (1998) : El abecé de la pragnática. Arco/libros. Madrid.

RIMEI HART, D. E. (1993) : "Some problems with the notion of literal meanings" . En A. Ortany (ed.) Metaphor and thought. Cambridge University Press. Cambridge, pp. 71-82.

SCHWOEBEI, John; DEWS, Shelly; WINNER, Ellen y SRTNIVAS, Kavitha (2000) : "Obligatory Processing of the Literal Meaning of Ironic Utterances: Further Evidence". Metaphor and Symbol, 15 (1 \& 2) , pp. 47-61.

SEARE, John (1979) : Expression and meaning. Cambridge University Press. Cambridge.

SEARE, John (1993) : 'Metaphor". EnA. Ortany (ed.) Metaphor and thaught. Cambridge University Press. Cambridge, pp. 83-111.

SPERBER, D. YWILSON, D. (1986) : Relevance: Commuication and cognition. Bladkwell, Oxford.

TODOROV, T. (1977) : Théories du symbol. Éditions du Seuil, Paris.

VERSCHUEREN, Jef (1999) : Para entender la pragmática. Gredas. Madrid, 2002.

WILSON, D. Y SPERBER, D. (1992) : «On verbal irony». Lingua, 87, pp. 53-76.

YUS Ramos, F. (1997) : "La teoría de la relevancia y la estrategia humorística de la incongnuencia-resolución". Pragnalingüística, 3-4, pp. 497-508.

ZAVALA, Iauro (1993): Humor, ironía y lectura. Las fronteras de la escritura literaria. Universidad Autónoma Metropolitana, Xochimilco. México. 